\title{
Veritism and the Normativity of Logic
}

\author{
forthcoming in Ratio \\ Comments and Suggestions Welcome \\ Nader Shoaibi \\ University of Indianapolis \\ nadershb@gmail.com
}

\begin{abstract}
The idea that logic is in some sense normative for thought and reasoning is a familiar one. Some of the most prominent figures in the history of philosophy including Kant and Frege have been among its defenders. The most natural way of spelling out this idea is to formulate wide-scope deductive requirements on belief which rule out certain states as irrational. But what can account for the truth of such deductive requirements of rationality? By far, the most prominent responses draw in one way or another on the idea that belief aims at the truth. In this paper, I consider two ways of making this line of thought more precise and I argue that they both fail. In particular, I examine a recent attempt by Epistemic Utility Theory to give a veritist account of deductive coherence requirements. I argue that despite its proponents' best efforts, Epistemic Utility Theory cannot vindicate such requirements.
\end{abstract}

Keywords - coherence norms, aim of truth, epistemic normativity, epistemic utility theory

\section{INTRODUCTION}

Suppose your friend, Yaya, is looking for a certain key. She is told by a trusted friend that it is in either of the two drawers of her desk. She looks in the first drawer and does not find it there. What should she believe? Well, at the very least it seems that she should not have the following combination of attitudes: believe that the key is in either of the two drawers, believe that it is not in the first, and believe that it is not in the second. And logical validity seems to play a crucial role in explaining why: that the key is in the second drawer follows by logical necessity from the key being in either of the two drawers and it is not being in the first.

But this raises the question: Why should Yaya heed the advice of logic? What is it about logic that gives it the authority to tell Yaya what she should or should not believe? In short, what is the source of the normativity of logic? Call this the 'source question'.

In this paper, I identify what I label the 'extrinsic view', which has a strong claim to being the standard view of the source of the normativity of logic (\$2). According to the extrinsic view, logic is to be understood in total isolation from our doxastic lives. On this view, logic can nevertheless have normative implications due to certain more fundamental normative facts about belief — that 
belief in some rough sense aims at the truth. My goal is to isolate two ways of making this rough idea more precise and argue that they both fail.

Here is the plan. After laying out the extrinsic view in $\$ 2$, I elaborate on the sense of the normativity of logic which is at issue throughout the paper in §3. I call this the 'response-guiding' role of logic. I then identify two ways of making the basic idea behind the extrinsic view more precise in $\S 4.1$ and $\S 4.2$. My primary focus will be on the latter, more promising account, according to which, irrationality of deductive incoherence is to be explained in terms of the notion of 'dominance' familiar from the literature on Probabilism. I argue that this account fails, because it undergenerates in the sense that it fails to identify all deductively incoherent states as irrational.

\section{THE EXTRINSIC VIEW}

It is easy nowadays to think that there is a straightforward answer to the source question. After all, the thought goes, didn't Frege teach us that logic is the science of the laws of truth, not the laws of 'taking-to-be-true', i.e., contingent principles governing our human psychology? According to this line of thought, our understanding of logic is wholly independent of anything that might be going on with anyone's beliefs. If there are normative implications of logic, this view holds, these should be understood on a par with the normative implications of other sciences like physics or chemistry: one ought to think in accordance with them, in so far as one aims to have true beliefs. Thus, just as a law of physics like $F=m a$ is not itself normative but can have normative implications for someone who wants to know what the force acting on an object of mass $m$, moving with acceleration $a$ is, so it is with logic. While the valid schemata of logic are themselves normatively inert, they can have normative implications if one wants to gain true beliefs and avoid false ones. ${ }^{1}$

A proponent of this view would say that all we need in order to make sense of the normativity of logic is, to use a phrase popularized by the widely-cited but unpublished MacFarlane (2004), a viable 'bridge principle' that connects logic, understood as an independent formal system, on the one hand, and normative claims about what we should or should not believe, on the other. Here is an example of a bridge principle:

(Wo-) if $P, Q \vDash R$, then you ought to see to it that if you believe $P$ and $Q$, then you do not disbelieve $R^{2}$

Note that (Wo-) is an example of what is sometimes called a 'wide-scope' norm (or rational requirement). This is because the normative operator — in this case 'ought' - takes wide-scope over the conditional. A wide-scope norm such as (Wo-) says that logic plays its normative role not by placing restrictions on individual attitudes, but by placing global restrictions on sets of doxastic attitudes. It thus does not require holding any particular belief; rather it rules out certain combinations of attitudes.

While it is also possible to come up with 'narrow-scope' bridge principles, my focus here will be on wide-scope principles such as (Wo-). After all, 'coherence' is most naturally thought of as a

\footnotetext{
${ }^{1}$ To be sure, there is controversy over Frege's views on these matters. I do not wish to take a stand on the interpretive question. For a defense of an interpretation of Frege along these lines, see MacFarlane (2017). ${ }^{2}$ where to disbelieve $R$ is to believe not- $R$ and thus is inconsistent with suspending judgment about $R$. I use MacFarlane (2004)'s label for this principle. It is worth noting that even thought (Wo-) is formulated with two premises, it is meant to hold generally for any number of premises. This will be significant in our discussion in $\S 4.1$ and $\S 4.2$. The recent debate over the normativity of logic is largely about identifying the correct bridge principle. See, for instance, Steinberger (2017b).
} 
matter of global, wide-scope requirements on sets of beliefs, which govern how beliefs stand in a network of other doxastic attitudes. My aim is to explore whether we can do this thought justice in our account of the normative role of logic. ${ }^{3}$

From this sketch, we can identify two components of the view:

1. Logical validity is to be defined independently of our doxastic lives.

2. Wide-scope coherence norms are vindicated by showing that following them contributes to some more fundamental epistemic good.

Call this the 'extrinsic view' of the normativity of logic. ${ }^{4}$

The most prominent version of the extrinsic view places a central emphasis on truth. According to this version, following Tarski (2002), logical validity is defined as the necessary preservation of truth in virtue of logical form. As for the second component, the idea is that logical norms have their normative implications in virtue of promoting truth as the most basic epistemic good. This latter assumption is sometimes referred to as 'veritism'. ${ }^{5}$

Despite the initial attractiveness of the extrinsic view, I will argue that the vertisit variety is not successful. My focus will be on the second component of the view. ${ }^{6}$ I will argue that even if

\footnotetext{
${ }^{3}$ See, for instance, Easwaran and Fitelson (2015) for an explicit use of 'coherence requirement' in this way. For the idea that coherence norms are in general wide-scope, see Broome (1999). One might worry that focusing on wide-scope norms unduly ignores Kolodny (2007)'s important contribution, which proposes that there are no such wide-scope norms, and that instead we can explain these apparent normativity of coherence norms in terms of narrow-scope which govern individual beliefs. While I have my doubts about Kolodny's view, I do not have the space to argue the point here. I will briefly return to Kolodny's alternative in $\S 5$.

${ }^{4}$ For a recent defense of the extrinsic view see Russell (2017).

${ }^{5}$ See Pettigrew (2018). In metaethics, views that attempt to provide means-end explanations of morality in terms of some fundamental value like the good or desirable are often labeled as 'consequentialist'. Following Berker (2013), we can characterize epistemic consequentialism as the view that takes certain epistemic goods as fundamental and tries to account for the rationality or reasonableness of our beliefs and belief-forming processes in virtue of their conduciveness toward bringing about these fundamental goods (244; See also Sylvan (2020) for the possibility of a non-consequentialist value monism. Thanks to an anonymous referee for drawing my attention to this possibility). There are different views about what these epistemic goods are: some count relevance or demonstrability as epistemic goods, but by far the most popular view is veritism, i.e., the view that the most fundamental good that belief aims at is truth, and that's what I will be focusing on. For more discussion see, for instance, Shah (2013), McHugh (2011), and Wedgwood (2017). See Berker (2013) for a review of how pervasive veritism is in contemporary epistemology. The extrinsic view can, thus, be understood as the marriage between the idea that logic must be defined independently of our reasoning and some version of epistemic consequentialism.

${ }^{6}$ In fact, both components face fundamental challenges. Against the first component, Field (2015) has argued that the truth-preservational account of logical validity fails. The details of this argument would take us far afield, but in very broad terms, his argument is meant to show that the concept of truth-preservation and our inter-theoretical concept of validity come apart and so the latter cannot be defined in terms of the former. And similarly, Bledin (2014), following Yalcin (2007), argues that, given our best account of indicative conditionals, certain licit cases of Modus Ponens would count as invalid. Even at this level of generality, however, we can see that a Field-style argument cannot conclusively reject the extrinsic view as it leaves open the possibility that there are alternative ways of defining the notion of validity that could ultimately succeed. Indeed, the expressed aim of Bledin (2014) is to advocate an alternative definition of validity in terms of preservation of acceptance at an information state (the informational notion of validity for short) as opposed to preservation of truth. Even if we find counterexamples against this alternative (as Santorio (2018), for instance, has recently attempted), this does not rule out the possibility that we might make yet other modification that would handle these new counterexamples.
} 
we can define logical validity in completely independent terms from our doxastic lives, the veritist version of the extrinsic view has trouble fully accounting for the normative role of logic.

\section{RESPONSE-GUIDANCE}

Before we begin, I should say more about what I have been calling the 'normative role of logic'. There are at least two paradigmatic cases which illustrate the specific idea I have in mind. By looking at these cases, my hope is that we can isolate a distinctive sense in which logic can play a normative role.

The first is first-personal deliberation. The original example involving Yaya is an instance of such a case. When Yaya wonders about where the key is, it seems that the logical relation between her current and possible beliefs plays a crucial role. In particular, it seems that logic can tell her that she should not hold on to her beliefs and also believe that the key is not in the drawer. ${ }^{7}$ This manifests itself in Yaya's resistance to believe that the key is not in the drawer, and her correctly pointing out the logical relations if there is a question about her response. In this way, we might say that logic helps to guide Yaya's deliberation about what to believe.

It is important to note that there is nothing in this idea that rules out something getting in the way of Yaya reasoning correctly: perhaps she is distracted or just not paying attention. In such cases, she would not be so guided and to that extent we might say that there is a defect in her belief system. But in cases where there are no such defects, logic seems to play a distinctive normative role in guiding her in her deliberations about what to believe.

It seems plausible to say that logic plays its response-guiding role through Yaya's 'grasp' of the logical relations. We must be careful, however, not to invite a charge of over-intellectualization. To be sure, what the grasp of the logical relations consists in cannot amount to an explicit belief that one holds. For, in that case, the kind of explanation that I have in mind would not be available in most cases. For one thing, most people have no formal education in logic, and even if they do, they do not seem to exploit it in their ordinary deliberation about what to believe. For another, if we assume that the grasp of the principles requires an explicit belief, then in cases where one is distracted or just does not see the logical relation or its relevance, it would seem that one would not count as grasping. But one's being distracted or inattentive is no reason to think that logical norms do not have application. The idea behind requiring a 'grasp' of the logical principles, then, should be construed in a way that make it possible for one to grasp and yet fail to conform to the norms. We might hope to achieve this by developing an account according to which the grasp amounts to some kind of implicit belief, which would then make the normative explanation that I have in mind possible. ${ }^{8}$

\footnotetext{
${ }^{7}$ Needless to say, one's view on what logic tells Yaya will depend on which bridge principle one endorses. I deliberately frame things here with (Wo-) in the background, but the point I am making does not assume it. In particular, I want to remain neutral about whether perhaps a stronger principle could work better in cases of first-personal deliberation.

${ }^{8}$ Arguably we need to say something stronger here. It might be that in light of the lesson from Carroll (1895)'s famous discussion of deductive inference we have to make room for a notion of 'grasp' that is more radically different from belief. So, we might say that in order for the grasp of the logical laws to play a role we must have some kind of know-how whose content is not the sort of thing that serves as another premise in a syllogism. For discussion see Ryle (1946:VII). There are roughly two ways in which I think this suggestion might unfold: first, we might think that the know-how is of general rules of inference which get implemented in particular cases of inference, or, alternatively, we might construe the know-how as an ability to make particular moves and view logic as a theoretical framework that seeks to systematically study our particular practices. The latter is the kind of 'conventionalism' which, according to Warren
} 
The other paradigmatic case which illustrates the response-guiding role of logic is what we might label 'constructive third-personal advice'. Suppose despite seeing that the key is not in the first drawer and having been told by a trusted friend that it is in either of the two drawers, Yaya still wonders where to look for the key. Observing Yaya, one can advise her to look in the second drawer. But notice that one can do so in one of two ways: either because one knows that the key is in the second drawer (by inference or observation); or because one knows that the key is in the second drawer and that Yaya is in a position to realize this. It is the second of these two ways which I am calling constructive advice. In such cases, one takes the advisee to have everything she needs in order to realize where the key is. Thus, for instance, one can tell her: 'Yaya, didn't you just look in the first drawer? And isn't it true that if it is not there, it has to be in the second drawer? ... Don't you think that you should look in the second drawer?' ${ }^{9}$

I call these cases of constructive advice, because the advice is given with the perspective of the agent in mind; the adviser tells the advisee what to believe given what she is in a position to know. In this way, this kind of advice is constructive in that it is typically meant to help the advisee see the right conclusion rather than revealing the conclusion without an accompanied rationale.

I am going to assume that these cases are sufficient to illustrate the basic idea of response-guiding role. In the next two sections, I argue that if logic plays this kind of role, then the variations of the extrinsic view which I will isolate must be rejected because they cannot account for this role. Before getting to the argument, however, there might be some reservation about the antecedent of that conditional, namely, that logic does play any such role. So, allow me to briefly say a few words about that.

One might suggest that the 'normative' role that logic plays is, to use a phrase used by Kolodny (2005), merely classificatory, helping us to categorize beliefs or constellations thereof as good or bad. On this view, logic gives us a set of norms or standards by which we can evaluate or assess beliefs or bits of reasoning from a third-personal perspective. A quick example helps to illustrate the idea of classificatory norms. Consider a toaster. Arguably, it is possible to derive what it is to be a good toaster from the function of a toaster, and from this we can construct ought-claims about toasters: that, for instance, toasters ought to toast bread. Obviously, however, there is no suggestion that these ought claims figure in any way in the operation of the toasters or, even more absurdly, that they can be used to give toasters constructive advice.

I do not deny that logic may play a classificatory role as this suggestion proposes: logic does seem to provide us with standards of evaluation according to which we might assess and criticize each other and constellations of beliefs, assertions, etc. However, what I am keen on pressing here is that, as the cases above illustrate, there seems to be more to the normative role that logic plays, and my hope is to explore what this idea would entail if we took it seriously. ${ }^{10}$

(2017), Quine (1936)'s famous arguments leaves open as a live possibility. I am attracted to this alternative, but cannot argue the point here. For a criticism of the 'know-how' proposal, see Besson (2019).

${ }^{9}$ Strictly speaking the advice may have to be something more like 'So, whatever you do you should not believe that the key is not in the second drawer' to fit with our wide-scope working bridge principle, (Wo-). The plausibility of the more positive advice might be due to the particular features of this example. I ignore this complication here.

${ }^{10}$ See Wallace (2011) for a similar claim against Thomson (2008). Needless to say, the debate between Wallace and Thomson is not about the normativity of logic specifically, but rather normativity in general. See also (Kolodny 2005, 555).

For further discussion on the different roles that logic plays, see Steinberger $(2017 a, b)$. 


\section{EXPLAINING THE NORMATIVITY}

\subsection{Take 1 - Guaranteed Inaccuracy}

So far we have seen that the extrinsic view wants to explain the normativity of a structural deductive norm such as (Wo-) in terms of the broad aim of truth for belief. But how exactly is that account supposed to go? In this and the next sections, I will isolate two ways of making that rough idea more precise and argue that neither can account for the response-guiding role of logic.

As a reminder, here is what (Wo-) says:

(Wo-) If $P, Q \vDash R$, then you ought to see to it that if you believe $P$ and $Q$, then you do not disbelieve $R$.

For ease of presentation, I proceed as if the widely accepted (Wo-) is the correct bridge principle. ${ }^{11}$ My argument in the following sections, however, does not depend on this assumption. What is required is that the correct bridge principle be a wide-scope deductive norm which rules out a combination of attitudes as all things considered irrational. ${ }^{12}, 13$

(Wo-) rules out being in the following doxastic state: believing the premises of a valid argument while disbelieving its conclusion. Let us use the term 'inaccurate attitude' for either a belief in a falsehood or a disbelief in a truth. The first way of making the extrinsic view more precise begins with the observations that the state ruled out by (Wo-) is guaranteed to involve at least one inaccurate attitude. Someone who believes the premises and disbelieves the conclusion of a valid argument cannot possibly get everything right about the world, no matter how the world actually is. And this seems to be something that one can know a priori without any concern about how the world actually is.

${ }^{11}$ MacFarlane (2004) ultimately ends up endorsing this principle. For other endorsements see Beall and Restall (2006), Broome (2005), and Field (2015).

${ }^{12}$ This means that $(\mathrm{Wr}-)$, the principle which replaces the strict normative operator in (Wo-) with 'have reason to' operator, is not targeted by my argument:

(Wr-) If $P, Q \vDash R$, then you have a reason to see to it that if you believe $P$ and $Q$, then you do not disbelieve $R$.

(Wr-) might seem like a more plausible principle because it allows for the reasons provided by logic to compete with other reasons that tone might have in a particular circumstance. In particular, the more general version of (Wr-) with indefinitely many premises does not have the unintuitive consequences that, as we shall see shortly, the general version of (Wo-) has in Preface cases. However, as Broome (1999) has observed, the logic's deductive requirements do seem to place a much stronger normative claim on us: 'The relation between believing $\mathrm{p}$ and believing $\mathrm{q}$ is strict. If you believe $\mathrm{p}$ but not $\mathrm{q}$, you are definitely not entirely as you ought to be' (406, quoted in MacFarlane (2004)). If this is right, then the more slack (Wr-) would not be an acceptable bridge principle. I agree with MacFarlane here that perhaps in light of the Preface cases we find that we have to accept something like (Wr-), but that we must first exhaust all our options in regard to a strict principle such as (Wo-).

${ }^{13}$ In light of our interest in the response-guiding role of logic, one might be inclined to opt for the ' $k$ ' variants of the bridge principle, where, in MacFarlane (ibid.)'s terminology, ' $k$ ' is an attitudinal qualifier that attached to the antecedent of the top-most conditional. Thus, for instance, (Wo-k) reads: 'If one knows that $P, Q \vDash R$, then you ought to see to it that if you believe $P$ and $Q$, then you do not disbelieve $R$ '. However, if, as I suggested before, the sense of 'grasp' that is necessary should be understood in terms of an 'implicit' belief (or even some sort of 'know-how'), then this addition would seem to be at best redundant or at worst a mistake. 
According to the first way of making the extrinsic view more precise, then, we can get a vindication of (Wo-) if we assume the following principle of doxastic rationality:

No Guaranteed Inaccurate Attitude (NGIA): A state that is guaranteed to involve an inaccurate attitude is irrational. ${ }^{14}$

Unfortunately, however, (NGIA) is simply too strong. For there are familiar contexts in which one can rationally hold attitudes which are guaranteed to be inaccurate. The most famous cases of this phenomenon are the so-called Preface and Lottery Paradoxes.

Let us focus on the Preface. Consider a scientist who does some careful fieldwork and writes a book with her findings, endorsing everything she writes in the book. However, reflecting on her work in the preface of the book, as any responsible scientist would admit, she claims that at least one of the things that she says in the book is false. Thus, she explicitly endorses the negation of the conjunction of the things that she already endorses in the book. Now, supposing that her endorsements are true expressions of her full beliefs, she is guaranteed to have a false belief. And yet it appears that there is nothing irrational about what she does. ${ }^{15}$

I think that the Preface is enough to show that (NGIA) is false. In fact, one might be inclined to think that it undermines the very idea of deductive coherence norms, since it shows that a generalized version of (Wo-) with many premises cannot be true. ${ }^{16}$

It might thus be suggested that (NGIA) should be restricted to apply only to arguments with a few (say, less than 3) premises. This, however, would seem to be an ad hoc restriction as there does not seem to be any independent reason to accept it. And, in any case, as we shall see in the next section, the second attempt at making the extrinsic view more precise has an elegant way of building this restriction in.

\subsection{Take 2 - Dominance}

This brings us to the second, more promising attempt at making the extrinsic view more precise. The basic idea is this: Instead of identifying irrational states by appeal to some property of an individual state, we can have a comparative principle of rationality which identifies an irrational state by comparing it to other states that one might be in with respect to how well they accurately

\footnotetext{
${ }^{14}$ I am using a fairly standard notion of 'doxastic rationality' here, which primarily applies to states. I assume that, in addition, the proponent of the extrinsic view holds that in general we ought to avoid being in an irrational state. Needless to say, this raises the question of how exactly this connection is to be established. However, I am focusing on a different question here: even supposing that the proponent of the extrinsic view can get an ought-claim from principles of doxastic rationality, can we trace the normativity of logic back to these principles? So, in what follows, I will move freely between 'state $S$ is irrational' and 'one ought to see to it that one is not in $S^{\prime}$.

${ }^{15}$ It is important to note that the Bayesian approaches, e.g., Christensen (2005), reject this way of describing the case because they hold that the proper attitudes of the scientist are not full beliefs, but degrees of belief; and that these have their own coherence requirements (e.g. the Kolmogorov axioms). According to these approaches, even though the contents of the scientist's beliefs would be contradictory if we took the attitudes to be full beliefs, because the scientist actually only has degrees of belief or credences and these obey the Bayesian axioms, there is no incoherence in the scientist's attitudes. The scientist can perfectly well have high credence in all the propositions while also having a high credence in the negation of their conjunction. For my purposes, I will not engage with this view because I share Kolodny (2007) and Easwaran and Fitelson (2015)'s intuition that there is a useful notion of full belief that we (ineliminably) take advantage of all the time.

${ }^{16}$ As I noted in footnote 2, even though (Wo-) is formulated with 2 premises, it is meant to hold generally with many premises. And the Preface is clearly a problem for this generalized version.
} 
represent the world. A natural way of developing this is to say that rationality minimally requires something like avoiding a state that is guaranteed to be worse off than some other state one can be in. ${ }^{17}$

Epistemic Utility Theory (EUT) gives us the tools to formulate this sketch more precisely. ${ }^{18}$ According to EUT, we can assign 'utilities' or 'scores' to the attitudes that we take towards a proposition as a function of whether the proposition is true or false. Because this is a version of veritism, these utilities are functions of the truth value of a given proposition. A utility function (eu) maps the truth value of a proposition and the agent's doxastic attitude toward that proposition (belief, disbelief, or suspension) to one of the three values for getting the facts right $(R)$, wrong $(-W)$, or neither (0): eu $:\{t, f\} \times\{B, D, S\} \rightarrow\{R,-W, 0\}$. Plausibly the function should be defined such that true beliefs and false disbeliefs (i.e., accurate attitudes) have the same positive value, namely, $R$; suspension of belief gets a value of 0 no matter what the truth value; and, false beliefs and true disbeliefs (i.e., inaccurate attitudes) have the same disvalue, namely, $-W$.

$$
\left\{\begin{array}{l}
e u(t, B)=e u(f, D)=R \\
e u(t, S)=e u(f, S)=0 \\
e u(f, B)=e u(t, D)=-W
\end{array}\right.
$$

A doxastic state, as before, is a set of doxastic attitudes (belief, disbelief, or suspension). We can represent this with a function (a belief function) that takes the set of propositions which the agent entertains to the set of our three doxastic attitudes: $\{B, D, S\}$. Using the above utility function, then, we can define an additive function that sums the utilities of all the attitudes in a state for any given possible world to generate an overall score for the state. ${ }^{19}$ This gives us a precise measure with which to compare doxastic states.

Given this machinery, let us look at a simple example. Suppose $P$ entails $Q$. Looking at the truth table for these two sentences, we have three possible truth value assignments. Since there are three possible attitudes - belief, suspension, and disbelief - there are 9 different states one can be in with respect to $P$ and $Q$. Let us focus on the case of the combination that (Wo-) rules out, namely, to believe $P$ and disbelieve $Q$. Call this state $s$. We have the following table for the utilities in each of the possible worlds:

\begin{tabular}{c|c||c|c}
$P$ & $Q$ & $s$ & $s^{*}$ \\
\hline$t$ & $t$ & $R-W$ & 0 \\
$f$ & $t$ & $-W-W$ & 0 \\
$f$ & $f$ & $-W+R$ & 0
\end{tabular}

Now given two fairly innocuous assumptions we can see why we should see to it that we are not in $s$ as (Wo-) recommends: First, a weak conservatism about epistemic value: $R<W .{ }^{20}$

${ }^{17}$ This idea is familiar from Bayesian epistemology. The so-called 'dominance argument' has been famously used, for instance, to defend Probabilism - the view that the credences in a rational credal state must be consistent with the probability axioms (See Joyce (1998); see also Pettigrew (2018) for further applications and references). See Easwaran (2016) and Easwaran and Fitelson (2015) for a survey and application in the case of coherence norms for full beliefs.

${ }^{18}$ My discussion here is based on Pettigrew (2017), which contains numerous references on the current research in the area.

${ }^{19}$ There are other ways of aggregating the scores for a state. The additive function, however, is by far the most intuitive. So, I will assume it for my purposes here. I believe that nothing in the argument hinges on this assumption.

${ }^{20}$ The notion conservatism here should not be confused with other uses - for instance, as used in Christensen 
This says that the disvalue of getting things wrong outweighs the value of getting things right. Intuitively, weak conservatism errs on the side of avoiding getting things wrong since, according to conservatism, that is more costly than the benefits of getting things right.

The second assumption we need in order to vindicate (Wo-) is the following plausible principle of rationality:

No Strict Dominance (ND): A state that is strictly dominated by another state the agent can switch to is irrational; ${ }^{21}$

where the notion of strict domination is defined as follows:

Some state $x$ is strictly dominated by another state $x^{\prime}$ if and only if one can do better in every possible world by switching to $x^{\prime} .{ }^{22}$

With the first assumption in place, we can see that the utility assigned to state $s$ will be negative at every possible world. But that would mean that $s$ is strictly dominated by the state of suspension of belief on both propositions, no matter what. For this state (call it $s^{*}$ ) gets the value of suspension which is always 0 in every possible world. Thus, the agent would be doing better with respect to the utility score in every possible world if she suspends her belief in both $P$ and $Q$. From the second assumption, it follows that $s$ is an irrational state to be in. Thus, we have a vindication of (Wo-) in the single-premise case: To be in the state that (Wo-) rules out, namely, to believe $P$ and disbelieve $Q$ is to be in a state in which one is guaranteed to do worse with respect to the utility score than some other state.

We thus seem to have a position which the proponent of the extrinsic view can happily occupy. When we deliberate about what to believe or when we try to give constructive advice, we must make sure to avoid the state of believing the premises of a valid argument and disbelieving the conclusion, because there is some other state one can adopt, regardless of how the world actually is, which does better with respect to accurately representing the world.

Note that because (ND) is weaker than (NGIA) it can handle the Preface cases with no problem. (ND) counts a state of believing the premises of a valid argument and disbelieving its conclusion as irrational only if the disvalue of getting things wrong outweighs the sum of the values of getting things right. We saw this in the form of the assumption that $R<W$ in the simple case of a single-premise argument. When we move from the single to multi-premise cases, the requirement would be $n R<W$, where $n$ is the number of premises involved. What this means is that once $n$ is large enough, as, for instance, in Preface cases, the condition $n R<W$ ceases to hold and so (ND) would not count the state of believing the premises and disbelieving the conclusion as irrational. So, (ND) manages to vindicate (Wo-) (assuming $2 R<W$, since (Wo-) is formulated for 2 premises), without vindicating the generalized multi-premise version, which, as we have seen, would be implausible in light of the Preface cases.

I shall argue, however, that (ND) is too weak, because even in 2-premise cases (and assuming $2 R<W)$, it fails to count all cases of deductive incoherence as irrational. As we go through the

(1994), which characterizes it as the idea 'that an agent is in some measure justified in maintaining a belief simply in virtue of the fact that the agent has that belief' (69).

${ }^{21}$ The proviso 'can switch to' is necessary because of the kind of principle we are interested in, namely, a deliberative one (See §3). I will return to this point below.

${ }^{22}$ There are variations on the basic formula here. For instance, 'weak dominance' says that $x$ is weakly dominated by $x^{\prime}$ if and only if $x^{\prime}$ is epistemically accessible and one can do better or equally in every possible world by switching to $x^{\prime}$. Since my discussion below does not depend on these variations, I will ignore them. 
argument, it is helpful to have a concrete case in mind. So, let us consider Yaya's case again. According to our utility theoretic machinery, Yaya, who believes that the key is in one of the two drawers of her desk and that it is not in the first while disbelieving that it is in the second (call this state $s_{1}$ ) could switch to another state which is guaranteed to be better no matter how thing turn out to be. This is the state (call is $s_{0}$ ) where she suspends judgment on all the propositions in the argument. Since, given (ND), being in $s_{1}$ is irrational, Yaya ought to see to it that she is not in it.

Now, the first thing to note is that for this result to hold $s_{0}$ and $s_{1}$ would have to be defined over the same set of propositions, since otherwise $s_{1}$ could accumulate positive values - at least in some worlds - over the propositions which $s_{0}$ does not range over, in which case the scales would tip in favor of $s_{1}$ in those worlds and so it would not be dominated by $s_{0} \cdot{ }^{23}$

So, our starting point in the story about why a state like $s_{1}$ (state of believing the premises of a 2-premise valid argument, and disbelieving its conclusion) is irrational would have to be:

(wtn) There is a state, $s_{0}$, defined over the same set of propositions which is guaranteed to do better than $s_{1}$.

Together with:

(ND) If there is a state defined over the same set of propositions the agent can switch to which is guaranteed to do better than $s_{1}$, then $s_{1}$ is irrational.

This seems to entail:

(c) $s_{1}$ is irrational.

The problem is that for this argument to work we need something stronger than (wtn). In particular, what we need is:

(wtn') There is a state, $s_{0}$, defined over the same set of propositions that the agent can switch to which is guaranteed to do better than $s_{1}$.

But there is reason to doubt that (wtn') is true. As I originally described the case, Yaya comes to have her belief that the key is in either of the two drawers through the testimony of a trusted friend. But notice that if Yaya suspends judgment on the propositions involved in the argument, in particular, that the key is in either of the two drawers, then there would have to be other beliefs of hers that need to be adjusted: for instance, her belief that her friend's testimony is sufficiently reliable. ${ }^{24}$ But in that case her new state would not be $s_{0}$, since it is not exactly like $s_{1}$ on the propositions other than those involved in the argument.

Note that the adjustments that Yaya would have to make apply not only to 'upstream' beliefs (such as the belief in the reliability of the friend's testimony), but also to her 'downstream' beliefs:

${ }^{23}$ The importance of the corresponding assumption in the case of credence functions is emphasized in Pettigrew (2018). Pettigrew is responding to Carr (2015), which argues that if we allow comparisons between partial credence functions (i.e., credence function that are not defined over all possible propositions), then any non-omniscient credence function would be dominated by some credence function, namely, a credence function defined over a larger set of propositions such that it tips the utility scale in favor of the latter function. Pettigrew proposes to avoid this problem by restricting the comparisons between states defined over the same set of propositions. See also Talbot (2017:fn. 22).

${ }^{24}$ Non-reductivists about testimony would resist this description: Yaya does not need another belief about the friend's reliability; the testimony is itself enough to justify her belief. If the reader finds this view compelling, then they can replace the belief about the reliability of testimony with whatever belief they find plausible as a candidate justifier for Yaya's belief. 
for instance, if Yaya's belief that, say, the key is in the house is based on her belief that it is in either drawer of the desk, then suspending on the latter belief would mean that she loses her justification for the former. So, an adjustment seems to be called for.

And this fact seems to be true of just about any belief: For any belief, there are some attitudes that she could not rationally have if she suspends judgment on that belief. ${ }^{25,26}$ If so, then we can't assume that the state that is identical to one's original state but suspends judgment on only the three propositions in the argument is necessarily one which one can switch to. That is because suspending a given belief can have repercussions for other attitudes that one has, which would make it impossible to suspend on only the propositions involved in the argument and leave everything else intact.

The upshot is this. To show that a given state is irrational by appeal to (ND), one must find a state, which (1) is defined over the same set of propositions, (2) suspends judgment on the propositions involved in the argument, (3) assigns exactly the same attitudes to every other proposition, and (4) is available for the agent to switch to. While we can certainly find a state that satisfies $1-3$, there is no reason to expect that such a state is guaranteed to be among those that are available for the agent to switch to. Since, according to (ND), we can only say that the state is irrational if we can find a dominant state which the agent can switch to, this implies that there is no guarantee that all deductively incoherent states are counted as irrational. ${ }^{27}$

It might be tempting to try to salvage the dominance argument by strengthening (ND). One might thus propose dropping the requirement that the strictly dominant state be available to the agent to switch to:

(ND'): If there is a state defined over the same set of propositions which is guaranteed to do better than $S_{1}$, then $S_{1}$ is irrational.

Unfortunately, however, this proposal fails to capture the appropriate sense of normativity. Recall that the target here is not merely a classificatory notion of normativity, but a response-guiding notion in the sense illustrated in cases of deliberation and constructive advice in $\S 3$. This seems to make the availability requirement indispensable. After all, according to the dominance account, the explanation of why one should avoid an inconsistent state is that being in that state is strictly

\footnotetext{
${ }^{25}$ See Rosa (2019) for a defense of some bridge principles concerning the attitude of suspension. Rosa defends the following principle: '(A) If $\phi_{1}, \ldots, \phi_{n} \vdash \psi$ then there is a reason against one's both believing all of $\phi_{1}, \ldots, \phi_{n}$ and suspending judgment about $\psi^{\prime}$. This principle may be sufficient for my purposes. Since Yaya already has a reason to avoid the state of suspending on whether the key is in either of the two drawers and believing some propositions which together entail this, that state is not available for her to switch to. However, I do not think that we need anything as ambitious as a bridge principle for my argument to go through. As long as it is true that for any belief there are some attitudes that the agent cannot rationally have if she suspends, my argument is in the clear. The reason why such a state is not available need not have anything to do with logic.

${ }^{26}$ Some might argue for a stronger claim: that there are certain kinds of attitudes which one cannot (not merely rationally, but conceptually) continue to have if one suspends on a given attitude. Suppose, for instance, that propositional attitudes are 'transparent' in the sense that one has a second-order belief that one has a given propositional attitude only if one actually has the attitude in question. In that case, my second-order belief that I believe that $P$ is a feature of my doxastic state which cannot survive if I suspend judgment on $P$. Transparency, in this sense, is admittedly a controversial thesis, but it serves well to illustrate the idea. I borrow this example from Berker (2013).

${ }^{27}$ It is worth noting that my argument, if successful, shows more than just (ND)'s inability to vindicate a deductive coherence norm such as (Wo-). It shows that (ND) has trouble vindicating any coherence requirement on belief (in the response-guiding sense) - whether deductive like (Wo-) or otherwise.
} 
dominated by another. But unless the dominant state is available for the agent to switch to, it is hard to see how this could enter into her deliberation about what to believe.

An analogy helps to clarify this point. Suppose I want to strip a wire. Let us assume that it is always better to use a wire stripper than to use one's teeth to strip a wire (which, let us assume, is a method I should never use). But suppose I do not have a wire stripper. What should I do? Does the fact that using a wire stripper is better than using my teeth show that I should not use my teeth? It seems clear to me that it does not. I want to know how to strip this wire now, and knowing that there is some better way which, as it happens, is not available to me, does not help me one bit in deciding what to do. Of course, this is not to say that, under the circumstances, stripping the wire using my teeth is a good idea. There may indeed be very good reasons in general - in this case, having to do with my dental hygiene - not to use my teeth to strip a wire. The point, rather, is that the fact that there is a better way than using my teeth to strip a wire cannot establish that, in general, I ought not to use my teeth for that purpose. For, in any given situation, it might be that the better way (using a wire stripper) is not available to me, in which case the unavailable possibility of the better way would not be a relevant consideration in my deliberations about what to do.

Just as the possibility of stripping the wire using the superior method is not enough to establish that in general one ought not use one's teeth for that purpose, so the proponent of the dominance-based argument cannot hope to establish that one ought to avoid a belief state by just pointing to the fact that there is some state which dominates it. The existence of this dominant state would be relevant to one's deliberations about what to believe only if it is available for the agent to rationally switch to.

If this is right, then we cannot strengthen (ND) by dropping the availability requirement. Admittedly, I have said very little about the notion of 'availability', but note that all that is needed to block the argument from (wtn) and (ND) to the conclusion that $s_{1}$ is irrational is that the set of states which are available to the agent be a proper subset of the set of all possible states. For, supposing that there is a state defined over the same set of propositions which is guaranteed to do better than $s_{1}$, we get the conclusion through (ND) that $s_{1}$ is irrational only if we can also assume that the dominant state is among those that are available for the agent switch to. But as long as the set of available states is a proper subset of the set of all possible states, we cannot assume that and therefore the argument fails.

\section{CONCLUSION}

In this paper, I have argued against two versions of the view that wants to explain the normativiy of structural, deductive coherence norms in terms of the aim of truth. According to the first version, we must avoid deductively incoherent states because doing so guarantees having an inaccurate attitude. Following a well-established tradition, I've argued that the Preface cases are enough to show that this idea is too strong. The second version, avoids this charge by opting for a comparative criterion of irrationality: i.e., that a state is irrational if there is another state the agent can switch to which does better with respect to accurately representing the world. However, I argued that this version is too weak: even when restricted to 2-premise arguments, it fails to count all cases of deductive incoherence as irrational.

Where does this leave us with respect to the question of the source of the normativity of logic? There are two options that remain open, which I would like to quickly sketch before closing. The first option is the 'evidentialist' view put forward originally by Niko Kolodny, which seeks to reject 
the very idea that there are any structural, deductive norms of coherence. ${ }^{28}$ According to the evidentialist proposal, the apparent normativity of logic can be explained by our responsiveness to reasons. In a nutshell, the idea is that someone who believes the premises of a valid argument and disbelieves its conclusion is failing to respond correctly to her reasons: Either she fails to see the reason against the premises or those in favor of the conclusion. In either case, what's bad about being incoherent is not that one violates some norm or principle; rather, the problem is with her responsiveness to reasons.

The evidentialist proposal can be viewed as a version of the extrinsic view in that it accepts the first component of the view - that logical validity is to be defined independently of our doxastic lives - and only slightly tweaks the second: The apparent coherence norms are vindicated by showing that following them contributes to the aim of having true beliefs and avoiding false ones.

The second option represents a much more radical departure. It rejects the very idea that logic is to be understood independently of our doxastic lives. According to this view, the normativity of logic is intrinsic to it as logic itself is a normative enterprise. ${ }^{29}$ One way of developing the intrinsic view is along broadly Kantian lines by claiming that logic is in the business of laying out (formally - in a sense of 'formal' to be clarified) the norms that constitutively govern belief and doxastic reasoning more generally. ${ }^{30}$

Needless to say, there is much more to say about each of these options and I want to remain completely neutral between them here. I hope to return to both options in future work.

\section{ACKNOWLEDGMENTS}

I wish to thank Fabrizio Cariani, Reza Hadisi, Tom Lockhart, Will Small, Julia Staffel, Daniel Sutherland, and Brian Talbot for helpful comments and suggestion on earlier versions. Thanks also to the audiences at Epistemology of Reasoning conference at the University of Cologne, Logic Rulez?! conference at Wiener Forum für Analytische Philosophie, APA Central, the Society of Exact Sciences Conference at University of Connecticut, Work in Progress talk series at the University of Illinois' Philosophy Department, and two anonymous referees.

\footnotetext{
${ }^{28}$ See Kolodny $(2005,2007)$. The view has attracted a lot of attention recently with many attempting to apply the basic idea to different structural, coherence norms. See, for instance, Kiesewetter (2017), though it should be noted that the latter's view is subtly, but importantly different from Kolodny. For a more recent example of an attempt to expand the application of the evidentialist proposal, see Lasonen-Aarnio (2020).

${ }^{29} \mathrm{~A}$ recent proponent of this view is Hartry Field. After arguing that the standard definitions of logical validity fails, Field (2015) proposes a quasi-realist account of logical validity, 'projectivism'. Field does not develop the account in much detail. Indeed, as he admits, he 'deliberately present[s] the general idea in such a way as to allow it to be filled out in more than one way' (27).

${ }^{30}$ See Oza (forthcoming) for further disucssion.
} 


\section{REFERENCES}

Beall, J. C. and Greg Restall (2006). Logical Pluralism. Oxford University Press (cit. on p. 6). Berker, Selim (2013). "The Rejection of Epistemic Consequentialism". In: Philosophical Issues 23.1, pp. 363-387 (cit. on pp. 3, 11).

Besson, Corine (Oct. 2019). "Logical Expressivism and Carroll's Regress". en. In: Royal Institute of Philosophy Supplements 86, pp. 35-62 (cit. on p. 5).

Bledin, Justin (2014). "Logic Informed". In: Mind 123.490, pp. 277-316 (cit. on p. 3).

Broome, John (Dec. 1999). “Normative Requirements". In: Ratio 12.4, pp. 398-419 (cit. on pp. 3, 6).

- (Oct. 2005). “Does Rationality Give Us Reasons?" In: Philosophical Issues 15.1, pp. 321-337 (cit. on p. 6).

Carr, Jennifer (2015). “Epistemic Expansions”. In: Res Philosophica 92.2, pp. 217-236 (cit. on p. 10).

Carroll, Lewis (1895). "What the Tortoise Said to Achilles". In: Mind 4.14, pp. 278-280 (cit. on p. 4).

Christensen, David (1994). "Conservatism in Epistemology". In: Noûs 28.1, pp. 69-89 (cit. on p. 8).

- (2005). Putting Logic in Its Place: Formal Constraints on Rational Belief. Oxford University Press (cit. on p. 7).

Easwaran, Kenny (2016). “Dr. Truthlove or: How I Learned to Stop Worrying and Love Bayesian Probabilities"." In: Nous 50.4, pp. 816-853 (cit. on p. 8).

Easwaran, Kenny and Branden Fitelson (2015). "Accuracy, Coherence and Evidence". In: Oxford Studies in Epistemology. Ed. by Tamar Szabó Gendler and John Hawthorne. Vol. 5. Oxford University Press, pp. 61-96 (cit. on pp. 3, 7, 8).

Field, Hartry (May 2015). “What Is Logical Validity?” In: Foundations of Logical Consequence. Oxford University Press, pp. 32-70 (cit. on pp. 3, 6, 13).

Joyce, James M. (Dec. 1998). “A Nonpragmatic Vindication of Probabilism”. In: Philosophy of Science 65.4, pp. 575-603 (cit. on p. 8).

Kiesewetter, Benjamin (2017). The Normativity of Rationality. English. Oxford University Press (cit. on p. 13).

Kolodny, Niko (2005). “Why Be Rational?” In: Mind 114.455, pp. 509-563 (cit. on pp. 5, 13).

- (2007). "How Does Coherence Matter?" In: Proceedings of the Aristotelian Society 107, pp. 229-263 (cit. on pp. 3, 7, 13).

Lasonen-Aarnio, Maria (Mar. 2020). “Enkrasia or Evidentialism? Learning to Love Mismatch". en. In: Philosophical Studies 177.3, pp. 597-632 (cit. on p. 13).

MacFarlane, John (2004). "In What Sense (If Any) Is Logic Normative for Thought". In: Unpublished Manuscript, pp. 1-25 (cit. on pp. 2, 6).

- (2017). "Is Logic a Normative Discipline?" In: Unpublished Manuscript, pp. 1-18 (cit. on p. 2).

McHugh, Conor (2011). "What Do We Aim at When We Believe?" In: Dialectica 65.3, pp. 369-392 (cit. on p. 3).

Oza, Manish (forthcoming). "The Value of Thinking and the Normativity of Logic". In: Philosophers' Imprint (cit. on p. 13). 
Pettigrew, Richard (2017). "Epistemic Utility and the Normativity of Logic". In: Unpublished Manuscript, pp. 1-28 (cit. on p. 8).

- (2018). "The Population Ethics of Belief: In Search of an Epistemic Theory X". In: Nous 52.2, pp. 336-372 (cit. on pp. 3, 8, 10).

Quine, W. V. (1936). "Truth by Convention". In: Philosophical Essays for A. Ln. Whitehead, New York: Longmans, Green and Co., pp. 250-273 (cit. on p. 5).

Rosa, Luis (2019). “Logical Principles of Agnosticism”. In: Erkenntnis 84, pp. 1263-1283 (cit. on p. 11).

Russell, Gillian (2017). “Logic Isn't Normative". In: Inquiry (cit. on p. 3).

Ryle, Gilbert (1946). "Knowing How and Knowing That". In: Proceedings of the Aristotelian Society 46, pp. 1-16 (cit. on p. 4).

Santorio, Paolo (2018). "Consequence for Informational and Probabilistic Discourse". In: Unpublished Manuscript. Central APA (cit. on p. 3).

Shah, Nishi (2013). "Why We Reason The Way We Do". In: Philosophical Issues 23.1, pp. 311-325 (cit. on p. 3).

Steinberger, Florian (July 2017a). "Consequence and Normative Guidance". In: Philosophy and Phenomenological Research (cit. on p. 5).

- (2017b). "The Normative Status of Logic". In: The Stanford Encyclopedia of Philosophy. Ed. by Edward N Zalta. Spring 201. Metaphysics Research Lab, Stanford University (cit. on pp. 2, 5).

Sylvan, Kurt L. (Jan. 2020). "An Epistemic Nonconsequentialism”. en. In: The Philosophical Review 129.1, pp. 1-51 (cit. on p. 3).

Talbot, Brian (2017). “Repugnant Accuracy”. In: Nous 00, pp. 1-24 (cit. on p. 10).

Tarski, Alfred (2002). "On the Concept of Following Logically". In: History and Philosophy of Logic 23.3, pp. 155-196 (cit. on p. 3).

Thomson, Judith Jarvis (2008). Normativity. Open Court Publishing (cit. on p. 5).

Wallace, R. Jay (2011). "'Ought", Reasons, and Vice: A Comment on Judith Jarvis Thomson's Normativity". In: Philosophical Studies 154.3, pp. 451-463 (cit. on p. 5).

Warren, Jared (2017). "Revisiting Quine on Truth by Convention". In: J Philos Logic 46, pp. 119-139 (cit. on p. 4).

Wedgwood, Ralph (2017). "Epistemic Teleology: Synchronic and Diachronic". In: Epistemic Consequentialism. Ed. by H. Kristoffer Ahlstrom-Vij and Jeffrey Dunn. Oxford University Press, pp. 1-25 (cit. on p. 3).

Yalcin, Seth (2007). "Epistemic Modals". In: Mind 116.464, pp. 983-1026 (cit. on p. 3). 